\title{
What evidence exists on how changes in marine ecosystem structure and functioning affect ecosystem services delivery? A systematic map protocol
}

\author{
C. Sylvie Campagne ${ }^{1,2^{*}} \mathbb{0}$, Joseph Langridge ${ }^{2}$, Joachim Claudet $^{3}$, Rémi Mongruel ${ }^{4}$ and Eric Thiébaut ${ }^{1}$
}

\begin{abstract}
Background: The current biodiversity crisis calls for an urgent need to sustainably manage human uses of nature. The Ecosystem Services (ES) concept defined as « the benefits humans obtain from nature » support decisions aimed at promoting nature conservation. However, marine ecosystems, in particular, endure numerous direct pressures (e.g., habitat loss and degradation, overexploitation, pollution, climate change, and the introduction of non-indigenous species) all of which threaten ecosystem structure, functioning, and the very provision of ES. While marine ecosystems often receive less attention than terrestrial ecosystems in ES literature, it would also appear that there is a heterogeneity of knowledge within marine ecosystems and within the different ES provided. Hence, a systematic map on the existing literature will aim to highlight knowledge clusters and knowledge gaps on how changes in marine ecosystems influence the provision of marine ecosystem services. This will provide an evidence base for possible future reviews, and may help to inform eventual management and policy decision-making.

Methods: We will search for all evidence documenting how changes in structure and functioning of marine ecosystems affect the delivery of ES, across scientific and grey literature sources. Two bibliographic databases, Scopus and Web of Science Core Collection, will be used with a supplementary search undertaken in Google scholar. Multiple organisational websites related to intergovernmental agencies, supra-national or national structures, and NGOs will also be searched. Searches will be performed with English terms only without any geographic or temporal limitations. Literature screening, against predefined inclusion criteria, will be undertaken on title, abstract, and then full texts. All qualifying literature will be subjected to coding and meta-data extraction. No formal validity appraisal will be undertaken. Indeed, the map will highlight how marine ecosystem changes impact the ES provided. Knowledge gaps will be identified in terms of which ecosystem types, biodiversity components, or ES types are most or least studied and how these categories are correlated. Finally, a database will be provided, we will narratively describe this evidence base with summary figures and tables of pertinent study characteristics.
\end{abstract}

Keywords: Ecosystem disservices, Coastal, Marine, Biodiversity, Nature's contribution to people, Spatio-temporal dynamics

\footnotetext{
*Correspondence: sylvie.campagne@sb-roscoff.fr

${ }^{1}$ Sorbonne Université, CNRS, Station Biologique de Roscoff, UMR7144,

Adaptation et Diversité en Milieu Marin, Place Georges Teissier, 29680 Roscoff, France

Full list of author information is available at the end of the article
}

\section{Background}

In the context of the current biodiversity erosion crisis, there is an increasingly urgent need to manage nature's contribution to people in a sustainable way and at a sustainable rate, thereby maintaining its potential to meet permits use, sharing, adaptation, distribution and reproduction in any medium or format, as long as you give appropriate credit to the original author(s) and the source, provide a link to the Creative Commons licence, and indicate if changes were made. The images or other third party material in this article are included in the article's Creative Commons licence, unless indicated otherwise in a credit line to the material. If material is not included in the article's Creative Commons licence and your intended use is not permitted by statutory regulation or exceeds the permitted use, you will need to obtain permission directly from the copyright holder. To view a copy of this licence, visit http://creativecommons.org/licenses/by/4.0/. The Creative Commons Public Domain Dedication waiver (http://creativeco mmons.org/publicdomain/zero/1.0/) applies to the data made available in this article, unless otherwise stated in a credit line to the data. 
the needs of the present and future human generations [1]. Nature's Contribution to People (NCP) and Ecosystem Services (ES) concepts have gained interest in their ability to highlight our dependency on nature and all the services we extract from it [2-4]. The concept of ES is relatively recent-being introduced in the late 1970sand has its roots in the recognition that ecosystems provide irreplaceable goods and services [5]. It has since been largely popularized by the Millennium Ecosystem Assessment as a way of thinking about the relationships between humans and nature [6]. Defined as «the benefits humans obtain from nature » [6], the ES concept helps in producing knowledge to support decisions aimed at promoting nature conservation. The related concept of NCP, popularized first by Intergovernmental Science-Policy Platform on Biodiversity and Ecosystem Services (IPBES) regional assessments, goes beyond ES by integrating a wider range of values (e.g., rational values) and the consideration of negative contributions of nature (also called disservices [7, 8]). NCP are defined as " all the contributions, both positive and negative, of living nature to people's quality of life » $[1,2]$.

These concepts allow the studying of socio-ecological systems by proposing to analyse the interactions between living components (humans and non-humans), which concerns rigorous approaches across different scientific disciplines-ecology (e.g., [9, 10]), economics (e.g., [11]), anthropology (e.g., [12, 13]), philosophy (e.g., [14]) or geography (e.g., [15]) - in order to describe the numerous interactions and to understand their scope. The ES concept allows for improving interactions between disciplines but also among scientists, managers, stakeholders and politicians by redefining the debates that exist around the conflicts between development and conservation [16]. The different ES can be divided into three main categories: (1) provisioning services, which are products obtained from ecosystems (e.g., foods, raw materials for industry); (2) regulation and maintenance services, which are benefits obtained from ecosystems (e.g., climate regulation, coastal protection); and (3) cultural services, which are non-material benefits obtained from ecosystems (e.g., Recreation activities) [17-19].

Marine ecosystems provide a wide range of ES. Several lists of marine ES are available in the literature such as Bordt and Sander [20], Kermagoret et al. [21], Barbier [22] or Mongruel et al. [13], generally inspired by the classification proposed in Liquete et al. [19] and Beaumont et al. [23]. For instance, based on the Common International Classification for Ecosystem Services (CICES) [24] and Liquete et al. [19], the French platform for the evaluation of ecosystems and ecosystem services listed the ES provided by marine ecosystems [13] as follows: food provision, raw materials from aquaculture, macro-algae production, molecules production, coastal protection, climate regulation, nutrient regulation, pest and disease control, symbolic, emblematic and aesthetic values, recreation and tourism, landscape amenity and knowledge production. They also considered "nursery function" and "maintenance of food webs" in their assessment even if these are sometime considered as functions [13] or as regulating services [19]. We also decided to include them. However, ecological functions like primary and secondary production provided by marine ecosystems and sometimes defined as support services were not included in this review $[21,25]$.

Marine ecosystems endure numerous direct drivers of change: mainly habitat loss and degradation, overexploitation, pollution, introduction of non-indigenous species, and climate change. All of which threaten the future sustainability of marine and coastal areas [26]. The magnitude of these direct drivers may also depend on indirect drivers such as demographic pressure, sociocultural context, economy, technological development, institutions and governance, and conflicts and epidemics. In 2008, Halpern et al. [27] showed in a multi-driver analysis that no area of the global ocean is unaffected by human influence and that more than $40 \%$ of the ocean, mainly in coastal areas (e.g., NE of USA, NW Europe, East Asia, Eastern Caribbean) are strongly affected. From 2008 to 2013, « sixty-six per cent of the ocean experienced increases in cumulative human impact [...], especially in tropical, subtropical and coastal regions, while only 13\% experienced decreases in response to management measures » [28]. Indeed, threats and pressures endured by marine ecosystems induce changes which have impacted marine ecosystem services and have negatively impacted human health and well-being, more specifically for Indigenous peoples and local communities dependant on fisheries [26]. For example Selim et al. [29] highlighted pathways linking fishing and climate (drivers) to Spawning Stock Biomass and recruitment of three demersal fish species (ecosystem processes) and the consequences for delivery of the Fisheries and ultimately on food provision (ecosystem services) (Fig. 1).

While marine ecosystems are increasingly included in new international legislation, the need to develop effective conservation and protection strategies remains. For instance, marine protected areas concern only $8 \%$ of the marine realm, only partly cover important sites for biodiversity and are not fully ecologically representative, wellconnected, and effectively managed [30]. It is therefore crucial to apply rigorous sustainable management practices in order to help guarantee the delivery of ES and conserve the multiple benefits provided by marine ecosystems, that so many people rely on [30, 31]. Hence, it first is particularly necessary to better understand such 


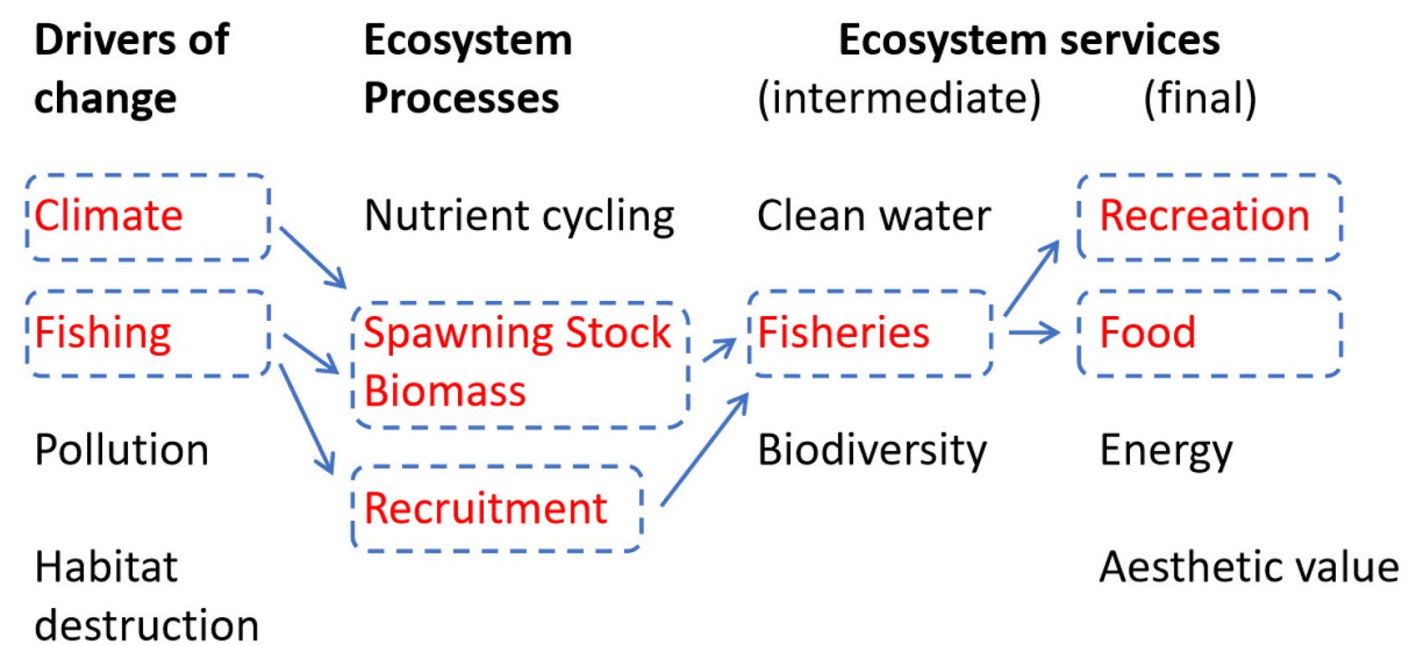

Fig. 1 Examples of how drivers of change can affect ecosystem services ( adapted from Selim et al. [29])

ecosystems and to highlight the related socio-ecological aspects.

In the ES literature, marine ecosystems receive less attention than terrestrial ecosystems: less than $9 \%$ of the ES literature [32]. In the numerous ES provided by marine ecosystems, food provision (i.e., fisheries and offshore aquaculture) seems to be by far the most intensively studied marine ES $[17,19]$. It can be related to the fact that some marine species groups are more assessed and studied like commercial species and top predator fish stocks [30]. In addition, another focus seems to be on specific ecosystems such as coral reefs, mudflats, and seagrass beds [13]. Also, knowledge on marine ecosystems seems to decrease with distance from the coastline [13]. Only a few studies have explored ES in deep-sea ecosystems [32]. Finally, the literature seems to focus on snapshot assessments instead on multi-time assessments in relation to the ecological dynamics.

The heterogeneity of knowledge in marine and coastal ecosystems and their services is a major obstacle to the effective use of scientific results by decision-makers. Thus, in order to structure existing knowledge and produce results that are useful for decision-making, a systematic map seems particularly relevant. A systematic map on the existing literature will highlight knowledge gaps and knowledge clusters on how changes in marine ecosystems influence the provision of marine ES. This will provide an evidence base for possible future reviews, and should help to inform eventual management and stakeholder decisions.

\section{Stakeholder engagement}

This systematic map is part of the InDySEM projectInfluence of ecological Dynamics on production and demand for marine Ecosystem Services, submitted to a call for research projects launched by The French Foundation for Research on Biodiversity-Center for Biodiversity Synthesis and Analysis (FRB-CESAB)-and is supervised by a scientific team and a methodological team. The scientific team is composed of researchers with expertise from ecology, economy, and sociology, with expertise on the different main marine ecosystems. The scientific team developed and built the project for the call and follow the project leader and the project officer during recurring meetings. Also, they validated the adjustment of the research question, the PECO elements, the search strings as well as all the ROSES elements. The methodological team is composed of systematic review and data analysis experts and follow all CEE methodological steps for systematic maps. The FRB-CESAB is a research structure with an international scope whose objective is to implement innovative work on the synthesis and analysis of existing data sets in the field of biodiversity.

\section{Objective of the review}

The principal objective of this review is firstly to record and synthesise all evidence on how spatio-temporal changes in marine biodiversity impact ES provided by these ecological systems. We will focus on changes in biodiversity from species level to ecosystems, including functional and structural diversity, and how these changes influence the services provided (i.e., provisioning, regulation and cultural). The associated disservicesnegative benefits from nature perceived by Humans-will also be taken into account where it is studied.

Indeed, the proposed mapping exercise differs from the 'traditional' ES literature, which often relies heavily on 
expert scientific knowledge and judgement for interpretation. This often results in a process that is rather subjective. By systematically mapping the existing literature, and by using recognised ES classification methods [19], our current strategy is expected to overcome previous biases and provide an objective and transparent overview.

Thus, in order to highlight knowledge gaps on how changes in marine ecosystems influence marine ES, a systematic map is chosen following specific PECO components (Table 1). The main goal is to collate existing literature and configure a map on the resulting evidence base concerning our primary question: what are the impacts of spatio-temporal dynamics of marine biodiversity such as changes in species abundance, and of ecosystems structure and functioning on the ecosystem services they provide.

In addition, the systematic map will summarise the evidence base in terms of the following secondary questions:

- How do the spatio-temporal dynamics of marine biodiversity affect ecosystem disservices?

- How are marine ecosystem services and disservices linked to natural or anthropogenic drivers?

\section{Methods}

This systematic map follows the methodological guidelines in accordance with the Collaboration for Environmental Evidence Guidelines and Standards for Evidence Synthesis [33] and conforms to the 'RepOrting standards for Systematic Evidence Syntheses' (ROSES) for Systematic Map Protocols presented by Haddaway et al. [34] (See Additional file 1 for the ROSES systematic map template of this study).

\section{Searching for articles Search string}

The research sub-strings are composed in accordance to the key elements of the question representing the
Population, the Exposure, and the Outcomes (Table 2). The search terms used for the sub-string on ES types includes different synonyms for each ES in order to be as inclusive as possible and comes from the different lists of marine ES based on Mongruel et al. [13], Global Ocean Accounts Partnership [18], and Liquete et al. [19]. The search terms for the sub-string on Exposure, which concerns changes in biodiversity (from species to marine ecosystems) are composed of key words synonymous to "change".

The search string was tested and constructed in Web of Science Core Collection (WOS) in order to have the highest efficiency and the best comprehensiveness related to the test list (See more in Additional file 2 for information of the building process of the search string).

\section{Search language}

Searches will be performed using English terms only. All relevant international literature published in English will be included in this systematic map. Indeed, this will include diverse bibliographic documents (e.g., books, journal articles, theses and technical reports).

\section{Bibliographic databases}

The 3 sub-strings of the search equation (Table 2) will be combined with "AND" and searched in title, abstract and keywords of the Scopus and WOS databases using the search tags "TITLE-ABS-KEY" and "TS", respectively. In Web of Science Core Collection, we will use exact search mode. All databases will be accessed with the subscription of the CNRS (Table 3).

\section{Web-based search engines}

Google Scholar, with the aid of the software Publish and Perish [35], will be used to retrieve scientific and grey literature (Table 3). Indeed, Google scholar's use of Boolean characters differs from WOS and Scopus and is limited in terms of number of characters and thus search terms [36]. Therefore, we adapted the search

Table 1 The different components of the systematic map

\begin{tabular}{ll}
\hline PECO elements & Definition(s) \\
\hline $\begin{array}{l}\text { Population } \\
\text { Marine biodiversity (ecosystems and species) }\end{array}$ & This will include all types of marine ecosystems and the species that they contain \\
$\begin{array}{l}\text { Exposure } \\
\text { Types of changes in marine biodiversity }\end{array}$ & All changes at all levels, from species to the ecosystems, functional and structural \\
$\begin{array}{l}\text { Comparator } \\
\text { Spatial difference - temporal difference }\end{array}$ & Spatial difference or difference in time \\
Outcomes & All qualitative or quantitative values of marine ecosystem services and disservices \\
Marine ecosystem services (and disservices) &
\end{tabular}


Table 2 Full search string grouped by sub-strings in relation to our concept categories

\begin{tabular}{|c|c|}
\hline Sub-string & Search terms \\
\hline Term 1 & (marine OR coast* OR ocean OR sea OR littoral OR maritime) AND (species OR biodiversity OR ecosystem OR ecological) \\
\hline \multicolumn{2}{|l|}{ POPULATION } \\
\hline \multicolumn{2}{|l|}{ Ecosystem } \\
\hline Term 2 & ("ecosystem service\$" OR "contribution to people" OR "ecosystem function\$" OR "ecosystem process" OR "landscape \\
\hline OUTCOMES & service\$" OR disservice\$ OR "provisioning service\$" OR ((provision OR production OR exploitation) AND (food OR fisher* \\
\hline Ecosystem service & $\begin{array}{l}\text { materials" OR "maintain* food webs" OR "life cycle maintenance and habitat protection" OR "habitat provision" OR } \\
\text { "nursery function" OR "regulation service\$" OR "climate regulation" OR "carbon sequestration" OR "weather regulation" } \\
\text { OR "atmospheric composition and conditions" OR "air quality regulation" OR "coastal protection" OR "water retention" } \\
\text { OR "nutrient regulation" OR "nutrient cycling" OR "pathogen regulation" OR "pest and disease control" OR "media- } \\
\text { tion of waste" OR "mediation of mass" OR "cultural service\$" OR "intellectual interaction" OR "physical interaction" OR } \\
\text { "experiential interaction\$" OR tourism OR recreation OR amenity OR aesthetic OR heritage OR symbolic OR "cognitive } \\
\text { effect\$" OR "knowledge production" OR education) }\end{array}$ \\
\hline Term 3 & (dynamic\$ OR impact\$ OR effect\$ OR variation\$ OR interaction\$ OR evolution OR change\$) \\
\hline
\end{tabular}

EXPOSURE

Dynamic

The asterisk (*) at the end of a search term/word is used to accept any variant of a base term. The dollar (\$) is used to accept single or no added characters; useful for acquiring plural and singular forms. Quotation marks were used to search the exact word order (or phrase)

Table 3 Databases and search engines used

\begin{tabular}{|c|c|c|c|}
\hline Platform & Databases and search engines & Years & Platform or provider \\
\hline Scopus & Scopus & $1788-2020$ & Elsevier \\
\hline \multirow[t]{9}{*}{ Web of science core collection } & Arts and humanities citation index & 1975-present & Clarivate analytics \\
\hline & Conference proceedings citation index: & 1998-present & \\
\hline & - Science & & \\
\hline & - Social science and humanities & 1998-present & \\
\hline & Current chemical reactions & 1985-present & \\
\hline & Emerging sources citation index & 2015-present & \\
\hline & Index chemicus & 1993-present & \\
\hline & Science citation index expanded & 1900-present & \\
\hline & Social sciences citation index & 1956-present & \\
\hline Google scholar & Google scholar & N/A & Google \\
\hline
\end{tabular}

string to correspond to what the review team deemed as the most important keywords (Table 4) and searched in the section "keywords" which searches in the title, abstract, and body text. We will export the first 300 search hits, in line with recommendations by Haddaway et al. [36].

\section{Organisational websites}

The following specialist organisations will be searched in order to collect reports with primary data related to our question.

(1) Intergovernmental agencies under the aegis of the UN
- Food and Agriculture Organization of the United Nations (FAO)

- United Nations Educational, Scientific and Cultural Organization (UNESCO)

- United Nations Environment Programme (UNEP)

(2) National or supra-national structures:

- US National Oceanic and Atmospheric Administration (NOAA)

- European Environment Agency (EEA)

(3) Non-governmental organization and international associations: 
Table 4 Search strings and search hits

\begin{tabular}{|c|c|c|c|c|c|}
\hline & Name & Section of search & Search string & Search hits & Date search \\
\hline \multirow[t]{2}{*}{ Literature databases } & Web of science & TS & cf. Table 2 & 17,329 & 20/07/2021 \\
\hline & Scopus & TITLE-ABS-KEY & cf. Table 2 & 24,051 & 20/07/2021 \\
\hline Online search engine & Google scholar & keywords & $\begin{array}{l}\text { (marine OR coastal OR ocean) AND } \\
\text { (species OR biodiversity OR ecosys- } \\
\text { tem) AND "ecosystem services" AND } \\
\text { change }\end{array}$ & 300 & $22 / 07 / 2021$ \\
\hline \multirow[t]{6}{*}{ Organisa-tional websites } & $\mathrm{FAO}$ & language: "English" & fishery & 50 & $27 / 08 / 2021$ \\
\hline & UNESCO & $\begin{array}{l}\text { Filter: language: "English"—-source: } \\
\text { "UNESCO"—AuthoCorporate-en-s: } \\
\text { "Intergovernmental Oceanographic } \\
\text { Commission"—nature of content: } \\
\text { "guide" AND "manuals and hand- } \\
\text { books" }\end{array}$ & marine ecosystem service & 50 & 19/08/2021 \\
\hline & UNEP & $\begin{array}{l}\text { Filters: "Reports and publications" } \\
\text { AND "Publication" AND "Report", } \\
\text { "Ecosystems and biodiversity" AND } \\
\text { "oceans and seas" }\end{array}$ & marine ecosystem service & 50 & 19/08/2021 \\
\hline & US NOAA & & ecosystem service & 15 & 19/08/2021 \\
\hline & EEA & & marine ecosystem service & 7 & 19/08/2021 \\
\hline & IUCN & & ecosystem service & 32 & $27 / 08 / 2021$ \\
\hline
\end{tabular}

- International Union for Conservation of Nature (IUCN)

For each organisational website, the search string is adapted with specific keywords with manual-systematic hand-searches and vary between the websites (Table 4). The main keywords used will be " marine ecosystem services » which contains the keywords of the population and the outcomes. Adaptation of the keywords used depends on the main topic of the organisational websites. For example, as the NOAA focuses on marine ecosystems, the search string will only be « ecosystem services ». For the FAO, the main keywords did not lead to any results, so we will focus on one ecosystem service: " fishery ». Again, the main keywords did not lead to any results in the IUCN publication websites, so we will focus only on « ecosystem service». Other websites were tested such as the websites of the Intergovernmental Panel on Climate Change (IPCC) and of the IPBES. Nevertheless, the main keywords of our search string did not lead to any results. These Intergovernmental websites only proposed review reports and no records with primary results. A maximum of 50 references will be considered in each organisational website.

\section{Estimating comprehensiveness of the search}

The search terms were tested in Web of Science Core Collection. The review team compiled a list of 30 articles that we considered as important and relevant for our respected fields and the research questions.
These articles are listed in Additional file 3. Search terms were modified and refined several times until the benchmark publications were retrieved. Indeed, words related to the population, the outcomes and the exposure were progressively added as described in Additional file 2. Concerning Web of Science Core Collection, 25 out of the 30 articles in our test list were retrieved with the search terms while three out of the 30 articles were not found at all in Web of Science Core Collection. With all the results extracted (Web of Science Core Collection, Scopus, and Google Scholar) 29 out of the 30 articles in our test list were retrieved, equating to a $96.7 \%$ comprehensiveness (Additional file 3 ). The only article we did not retrieve was Roessig et al. [37]. We tried different search strings, nevertheless the numbers of documents found with other search strings retrieving Roessig et al. [37] were either unmanageably high or other documents in the test list were not found. The current search string at $96.7 \%$ is the best compromise.

\section{Organisation of search hits}

Once the extraction of records from each database and website is completed, we will first reassemble all bibliographic information from all the different databases in one file using Excel software and Mendeley. This will allow us to collate all records retrieved from each database. Then we will remove clear and partial duplicates based on similar DOI and similar titles. 


\section{Article screening and study inclusion criteria Screening strategy}

In order to select the relevant literature to be analysed, a three-stage filtering process will be undertaken in accordance with pre-defined screening and study eligibility criteria. Firstly, title screening will be performed followed by abstracts screening, then full-text screening. If we are unable to retrieve/find the full-text of a record where its abstract was accepted during abstract screening, then the article's full text will not be screened. The proportion of documents missing relative to accepted records will be provided. The search for full texts will be undertaken for all accepted abstracts with the use of journal subscriptions from the CNRS and the Sorbonne University. If the articles cannot be found, request for texts may be made via ResearchGate (www.researchgate.net) or the authors may be contacted through ResearchGate or directly by email. Following a conservative approach, if articles are not clearly in the inclusion criteria or do not clearly follow a reason for exclusion (details in the Eligibility criteria section), the articles will be kept for screening at the next eligibility stage.

\section{Consistency checking}

To test the consistency of the screening process, a Cohen's Kappa test [38] will be performed between two reviewers (C.S.C. and E.T.). Accordingly, 1000 titles, 10\% of the abstracts selected, then $10 \%$ of retained full texts will be pre-screened by the two reviewers separately to check for consistency in the interpretation of eligibility criteria. Due to resource limitations and the considerable number of records within all databases used (more than 40,000 in total-see Table 4), it will not be possible to do the Kappa test on $10 \%$ of the titles. If the Kappa score is less than 0.6 (which would mean a lack of consistency) the sources of disagreement will be analysed and discussed in order to resolve the reasons for disagreement. Another set of articles will then be screened and the Kappa scores re-calculated. This will be repeated until statistical agreement is reached i.e., the Kappa score is greater than 0.6 [39]. After which, all (if any) remaining disagreements will be discussed before beginning the full screening process.

\section{Eligibility criteria}

The selection of records will depend on the inclusion and exclusion criteria presented in Table 5. The inclusion/ exclusion decisions at each screening stage will be documented. A list of records will be provided with reasons for exclusion during the full-text (see Additional file 4).

Concerning the title screening, only articles with a clear mention of "marine ecosystems" and "ecosystem services" with the wording of ES or ES-related concepts directly mentioning an ES will be accepted (see list Liquete et al. [19], or Préat [17] for ES list of marine ecosystems). In the abstract screening process, we will consider in addition to the previous criteria, the Exposure and Comparator. If an article respects the inclusion criteria of population and outcome but not of exposure - (i.e., article on marine ecosystem and ES but without consideration of spatial or temporal difference), the article will be excluded. As we are looking for ES values, we will not consider documents only focusing on methods, reviews or on policy analysis. The full-text screening will consider the previous criteria and will also consider a new

Table 5 Eligibility criteria

\begin{tabular}{|c|c|c|c|}
\hline Criteria & Screening Steps & Inclusion criteria & Exclusion criteria \\
\hline Population & Title & $\begin{array}{l}\text { Titles on any marine biodiversity, marine species, } \\
\text { habitats and ecosystems }\end{array}$ & $\begin{array}{l}\text { OUT: any title referring to ecosystem services provided } \\
\text { by terrestrial and/or fresh water ecosystems }\end{array}$ \\
\hline \multirow[t]{2}{*}{ Outcomes } & Title & $\begin{array}{l}\text { Titles on any marine ecosystem service (as well as } \\
\text { related terms of ES like "nature contributions to people" } \\
\text { and all the relevant terms in the search string) no mat- } \\
\text { ter the types of values }\end{array}$ & $\begin{array}{l}\text { OUT: titles that address commercial species criteria with } \\
\text { indicators other than the stock or the population size of } \\
\text { the species }\end{array}$ \\
\hline & & $\begin{array}{l}\text { Titles on ecosystem service of food supply in terms of } \\
\text { indicators of stock or population size of commercial } \\
\text { species }\end{array}$ & \\
\hline Exposure & Abstract & $\begin{array}{l}\text { Abstracts have to present a change (spatial or tem- } \\
\text { poral change) in marine biodiversity, marine species, } \\
\text { habitats and ecosystems or in ecosystem services }\end{array}$ & $\begin{array}{l}\text { OUT: abstracts presenting an assessment-a one-time } \\
\text { state-of the population or of the outcomes }\end{array}$ \\
\hline Comparator & Abstract & Abstracts presenting temporal and spatial differences & OUT: abstracts only assessing ES \\
\hline Temporal period & Abstract & $\begin{array}{l}\text { Abstract analysing data covering period at least part of } \\
\text { the Twentieth century and/or the twenty-first century }\end{array}$ & $\begin{array}{l}\text { OUT: abstracts analysing data covering period ended } \\
\text { before } 1900 \text { (e.g., Palaeoecology analysis) }\end{array}$ \\
\hline Outcomes & Full-text & $\begin{array}{l}\text { Full-texts have to contain qualitative or quantitative } \\
\text { values of marine ecosystem services and disservices }\end{array}$ & $\begin{array}{l}\text { OUT: full-texts without qualitative or quantitative values } \\
\text { of marine ecosystem services and disservices }\end{array}$ \\
\hline
\end{tabular}


criteria related to the outcomes with the need to contain ES values.

Each screening stage will be undertaken with a conservative approach in respect to our selection criteria. If qualifying information is unclear or unknown then records in question will be passed to the next eligible screening stage.

\section{Data coding strategy}

A thorough metadata extraction for the map will be performed by the two members of the mapping team. The metadata form will be tested on 20 articles in order to test its applicability. Each selected article will be double coded. If, due to resource limitations, true double coding is not possible, an a posteriori cross-check will be carried out and potential disagreements will be discussed until a consensus is reached. Any missing information will be highlighted with an 'unknown. For each retained article after the screening process, the following metadata will be extracted and coded (Additional file 4):

\section{Bibliographic information}

Authors, Article Title, Keywords, Journal, Abstract, Affiliation first author, Country affiliation, DOI, Type of document (peer-reviewed article, book, book chapter, conference object, $\mathrm{PhD}$ thesis, technical report, or other), Sources of funding, Year of publication.

\section{Information to be coded}

All items which will be coded in the selected articles are presented in Table 6. Each option of each item will be coded «yes» or « no». If items present options, a free space for the text present in the article is added.

For the services classification, we used an adaptation of Préat [17] and leave the option to right the name of the ES if it is not in the list of ES proposed.

\section{Complementary information to be coded}

In addition, on the bibliographic information and information related to the PECO elements, information on the type of documents, the type of bibliographic content and if it is primary data made in the document will be coded. Also, we will code information about the types of pressures and management in order to know more about the origin of the change of marine ecosystems.

\section{Study validity assessment}

The validity of evidence will not be assessed within this systematic map but we will code study design elements that may provide some preliminary indication of internal validity. Thus, two additional types of information will be coded. The 'bibliographic content' i.e., study, review, modelling, meta-analysis. In addition, the type of data will be reported in 'primary data' with an "yes » if the record produces primary data (Table 6).

\section{Study mapping and presentation}

The results will be synthesized using a narrative approach, graphs and summary tables to highlight the state of the evidence related to our primary and secondary questions. We will first depict the increase in the number of papers addressing the links between the changes of marine biodiversity and ecosystems and their provision of ES.

Summary tables and/or graphs will be created to identify the types of ecosystems, the biodiversity metrics, the ES category, and the temporal and spatial scale of each study. The types of ecosystems will be determined following the EUNIS (European Union Nature Information System) habitat classification which is a hierarchical comprehensive pan-European system for habitat classification. According to this typology at level 2, eight main categories of marine habitats will be considered: one category for pelagic habitats, one category for ice-associated marine habitats and six categories for benthic habitats depending on depth and substrate type. Although this typology has been developed for European waters, its application to the world's oceans does not raise any major concerns. This list of eight habitats will be completed by specific charismatic habitats such as tidal marshes or seagrass meadows. To describe which facet of marine biodiversity is monitored to depict changes in marine populations or ecosystems, we will consider three classes of Essential Biodiversity Variables [44]: species populations, community composition, and ecosystem structure. For each class which corresponds to three different levels of biological organization (i.e., population, community, ecosystem), three essential characteristics of diversity will be used: (i) the taxonomic diversity, which is the number of different biotic entities; (ii) the structural biodiversity, which is the distribution of biological entities; and (iii) the functional diversity, which is the diversity of functions or functional traits [40]. The ES will be classified following the classification framework of Préat [17] adapted from Liquete et al. [19] and Barbier [22]. This classification relies on the CICES, which includes three groups of ES subdivided into different categories: provisioning services, regulation services, and cultural services. In comparison with the framework proposed by the Millennium Ecosystem Assessment [45], this classification framework excludes the supporting services. As there is no classification of disservices commonly used the disservices would be reported as written in the records and then an analysis of the main concept or words used would be made. 
Table 6 Meta-data to be extracted from the selected articles

\begin{tabular}{|c|c|c|}
\hline Item & Description & References \\
\hline \multicolumn{3}{|l|}{ Population } \\
\hline Ecosystem type & $\begin{array}{l}\text { A1 - Intertidal rock and other hard substrates; A2-Intertidal sediment; } \\
\text { A3-Subtidal rock and other hard substrates; A4-Circalittoral rock and other } \\
\text { hard substrates; A5-Subtidal sediment; A6-Deep-sea habitats; A7-Pelagic } \\
\text { habitats; A8-Ice-associated marine habitats (sub-categories of EUNIS would } \\
\text { be classified in its higher categories) + free space for others ecosystem types }\end{array}$ & $\begin{array}{l}\text { Classification EUNIS Niveau 2- } \\
\text { European Commission }\end{array}$ \\
\hline Specific ecosystem & $\begin{array}{l}\text { Tidal marsh; Seagrass; Coral reefs; Mangroves; Kelp forests + free space for others } \\
\text { specific ecosystem types }\end{array}$ & \\
\hline Level of biological organisation & Species; population; community & Lausch et al. [40]; Bruford et al. [41] \\
\hline Characteristics of biodiversity & Taxonomic; structural; functional & \\
\hline \multicolumn{3}{|l|}{ Outcomes } \\
\hline Number of ES per categories & $\begin{array}{l}\text { Number of ES for the following ES categories: Provisioning services; regulating } \\
\text { services; cultural services; disservices }\end{array}$ & \\
\hline ES & $\begin{array}{l}\text { Food provision; raw materials; genetic materials; water provision; water puri- } \\
\text { fication; air quality regulation; coastal protection; climate regulation; weather } \\
\text { regulation; nutrients cycling; habitat provision; pest and disease control; } \\
\text { symbolic and aesthetic values; recreation and tourism; cognitive effects; } \\
\text { educational opportunities (related ES terms would be considered in each ES } \\
\text { type) + free space for other ES }\end{array}$ & Préat [17] \\
\hline EDS & $\begin{array}{l}\text { Free space to record all EDS assessed (e.g., release of greenhouse gases, wild } \\
\text { animal attacks) }\end{array}$ & \\
\hline ES-EDS components & Potential; capacity; use/flow; demand; preferences; desires & \\
\hline ES-EDS values & Economic; social; biophysical & \\
\hline \multicolumn{3}{|l|}{ Exposure/Comparator } \\
\hline Scale of study area & $\begin{array}{l}\text { L: local; N-: subnational; N: national; N+: supranational; C: continental; G: } \\
\text { global; N: no case study }\end{array}$ & Liquete et al. [19] \\
\hline Location of analysis & List of country names; no application; global & \\
\hline Specific location & Freespace & \\
\hline \multirow[t]{2}{*}{ Temporal scale of analysis } & Interval (time elapsed between successive temporal replicates): free space & \\
\hline & Duration (time elapsed between first and last temporal replicates): free space & \\
\hline Time frame & Past; present; future & \\
\hline Spatial scale of analysis & Free space (e.g., « between a MPA and a no-MPA area ») & \\
\hline Type of data & Observation; prediction & \\
\hline \multicolumn{3}{|l|}{ Complementary information } \\
\hline Bibliographic document type & $\begin{array}{l}\text { Journal article; book; book chapter; conference object; PhD thesis; technical } \\
\text { documentation }\end{array}$ & Following Langridge et al. [42], \\
\hline Bibliographic content & Study; review; modelling; meta-analysis; other & \\
\hline Primary data & Yes; no & \\
\hline Pressure type & $\begin{array}{l}\text { Land/sea use change; direct exploitation; climate change; pollution; invasive } \\
\text { alien species + free space for other pressures }\end{array}$ & IPBES [43] \\
\hline Management type & $\begin{array}{l}\text { Status of protection; conservation; specific management }+ \text { free space for other } \\
\text { type of management }\end{array}$ & \\
\hline
\end{tabular}

In addition, to depict the source of impact on marine biodiversity and the provision of ES, we will consider the five main direct drivers of change as identified by the IPBES [43]: (i) sea use change leading to habitat degradation, (ii) exploitation of marine resources, (iii) climate change, (iv) pollution, and (v) introduction of non-indigenous species. As management measures can counteract the negative effects of human stressors on marine biodiversity, we will also take into account the implementation of marine protected areas as a human intervention that may influence the ecosystem health and the provision of marine ES.

Heat maps will be used to identify knowledge clusters and knowledge gaps. A particular attention will be given to the links between habitat categories and ES types, and between biodiversity classes and levels of biological organization and ES. The results of the map will contribute to identifying the variability of the state of knowledge 
according to the ecosystems and their distance from the coast and the diversity of interactions between marine biodiversity and ecosystem services. We hypothesize a decrease in knowledge in offshore waters and deep-sea habitats, a focus on the most emblematic or charismatic habitats as opposed to ordinary nature, while offshore habitats will be associated with global and common goods issues such as climate change.

The results will be used to identify key meta-data variables for a meta-analysis planned after the map review.

\section{Supplementary Information}

The online version contains supplementary material available at https://doi. org/10.1186/s13750-021-00251-x.

Additional file 1. Excel files ROSES protocol filed.

Additional file 2. Search string evolution and estimating comprehensiveness of the search.

Additional file 3. Test list of articles for assessing comprehensiveness.

Additional file 4. Spreadsheet outlining the meta-data extraction methods.

\section{Acknowledgements}

CSC thanks Sini Savilaakso for advice. CSC, JL and ET thank Nicolas Casajus, Data Scientist of the Synthesis Center of the French Foundation for Research on Biodiversity (FRB-Cesab) for all his advice on the planned data extraction.

\section{Authors' contributions}

All authors contributed to the conception and the design of the protocol. CSC was the major contributor in writing the manuscript. ET contributed in writing the manuscript. JL contributed more specifically to all elements of the methods and CEE guidelines. JC and RM provided comments on the manuscript. All authors read and approved the final manuscript.

\section{Funding}

This research is a product of the IndySEM project, funded by the synthesis center CESAB of the French Foundation for Research on Biodiversity (FRB; www.fondationbiodiversite.fr).

\section{Availability of data and materials}

Data sharing is not applicable to the systematic map protocol in that no datasets were generated for this article. Datasets produced by the systematic map will be shared in open access.

\section{Declarations}

Ethics approval and consent to participate

Not applicable.

\section{Consent for publication}

Not applicable.

\section{Competing interests}

Authors declare having no competing interests.

\section{Author details}

'Sorbonne Université, CNRS, Station Biologique de Roscoff, UMR7144, Adaptation et Diversité en Milieu Marin, Place Georges Teissier, 29680 Roscoff, France. ${ }^{2}$ Fondation pour la Recherche sur la Biodiversité, Centre de Synthèse et d'Analyse sur la Biodiversité (FRB-Cesab), 5 rue de l'école de médecine, 34000 Montpellier, France. ${ }^{3}$ National Center for Scientific Research, PSL Université Paris, CRIOBE, CNRS-EPHE-UPVD, Maison des Océans, 195 rue
Saint-Jacques, 75005 Paris, France. ${ }^{4}$ Ifremer, Univ Brest, CNRS, UMR 6308, AMURE, Unité d'Economie Maritime, IUEM, 29280 Plouzane, France.

Received: 28 September 2021 Accepted: 28 November 2021

Published online: 13 December 2021

\section{References}

1. IPBES. Global assessment report on biodiversity and ecosystem services of the Intergovernmental Science-Policy Platform on Biodiversity and Ecosystem Services. 2019.

2. Díaz S, Pascual U, Stenseke M, Martín-López B, Watson RT, Molnár Z, et al. Assessing nature's contributions to people: recognizing culture, and diverse sources of knowledge, can improve assessments. Science. 2018;359:270-2. https://doi.org/10.1126/science.aap8826.

3. Harrison PA, Harmáčková ZV, Karabulut AA, Brotons L, Cantele M, Claudet , et al. Synthesizing plausible futures for biodiversity and ecosystem services in Europe and Central Asia using scenario archetypes. Ecol Soc. 2019. https://doi.org/10.5751/ES-10818-240227.

4. Hill R, Díaz S, Pascual U, Stenseke M, Molnár Z, Van Velden J. Nature's contributions to people: weaving plural perspectives. One Earth. 2021;4:9105. https://doi.org/10.1016/j.oneear.2021.06.009.

5. Mongruel R, Méral P, Doussan I, Levrel H. L'institutionnalisation de I'approche par les services écosystémiques : dimensions scientifiques, juridiques et politiques. Roche P, Geijzendorffer I, Levrel H, Maris V. (Coord.), Val. la biodiversité Serv. écosystémiques Perspect. Interdiscip. éditions QUAE, Paris, Fr. 2016. pp. 191-216.

6. MEA. Millenium ecosystem assessment. Washington DC: Island Press; 2005.

7. Shackleton CM, Ruwanza S, SinassonSanni GK, Bennett S, De Lacy P, Modipa R, et al. Unpacking Pandora's box: understanding and categorising ecosystem disservices for environmental management and human wellbeing. Ecosystems. 2016;19:587-600. https://doi.org/10.1007/ s10021-015-9952-z

8. Campagne CS, Roche PK, Salles J-M. Looking into Pandora's box: ecosystem disservices assessment and correlations with ecosystem services. Ecosyst Serv. 2018. https://doi.org/10.1016/j.ecoser.2018.02.005.

9. Vihervaara P, Mononen L, Nedkov S, Viinikka A. Biophysical mapping and assessment methods for ecosystem services. 2018;72.

10. Lavorel S, Locatelli B, Colloff MJ, Bruley E. Co-producing ecosystem services for adapting to climate change. Philos Trans R Soc B Biol Sci. 2020. https://doi.org/10.1098/rstb.2019.0119.

11. Kubiszewski I, Costanza R, Anderson S, Sutton P. The future value of ecosystem services: global scenarios and national implications. Ecosyst Serv. 2017:26:289-301. https://doi.org/10.1016/j.ecoser.2017.05.004.

12. Santos-martín F, Martín-lópez B, et al. Social assessment methods and applications. 2016.

13. Mongruel R, Kermagoret C, Carlier A, Scemama P, Le Mao P, Levain A, et al. Milieux marins et littoraux : évaluation des écosystèmes et des services rendus. Rapport de l'étude réalisée pour le compte du programme EFESE. 2019.

14. Maris V. Nature à vendre, les limites des services écosystémiques. 2014.

15. Drakou EG, Virdin J, Pendleton L. Mapping the global distribution of locally-generated marine ecosystem services: the case of the West and Central Pacific Ocean tuna fisheries. Ecosyst Serv. 2018;31:278-88.

16 Harrison PA, Dunford R, Barton DN, Kelemen E, Martin-Lopez B, Norton $L$, et al. Selecting methods for ecosystem service assessment: a decision tree approach. Ecosyst Serv. 2017. https://doi.org/10.1016/j.ecoser.2017. 09.016.

17. Preat N. Development of environmental sustainability impact assessment methods for marine sourced products. PhD thesis, Ghent University, Belgium. 2021.

18. Global Ocean Accounts Partnership. Technical guidance on ocean accounting for sustainable development. United Nat. 2019.

19. Liquete C, Piroddi C, Drakou EG, Gurney L, Katsanevakis S, Charef A, et al. Current status and future prospects for the assessment of marine and coastal ecosystem services: a systematic review. PLoS ONE. 2013;8: e67737. https://doi.org/10.1371/journal.pone.0067737. 
20. Bordt M, Saner MA. A critical review of ecosystem accounting and services frameworks. One Ecosystem. 2018. https://doi.org/10.3897/oneeco. 3.e29306.

21. Kermagoret C, Claudet J, Derolez V, Nugues MM, Ouisse V, Quillien N, et al. How does eutrophication impact bundles of ecosystem services in multiple coastal habitats using state-and-transition models. Ocean Coast Manag. 2019;174:144-53. https://doi.org/10.1016/j.ocecoaman.2019.03. 028.

22. Barbier EB. Marine ecosystem services. Curr Biol. 2017;27:R507-10. https:// doi.org/10.1016/j.cub.2017.03.020.

23. Beaumont NJ, Austen MC, Atkins JP, Burdon D, Degraer S, Dentinho TP, et al. Identification, definition and quantification of goods and services provided by marine biodiversity: implications for the ecosystem approach. Mar Pollut Bull. 2007;54:253-65. https://doi.org/10.1016/j. marpolbul.2006.12.003.

24. Haines-Young R, Potschin M, Haines-Young R, Potschin M. CICES V4.3report prepared following consultation on CICES version 4, AugustDecember 2012. EEA Framework Contract No EEA/IEA/09/003 2013.

25. Bindoff NL, Cheung WWL, Kairo JG, Aristegui J, Guinder VA, Hallberg R, et al. Changing ocean, marine ecosystems, and dependent communities. IPCC Spec Rep Ocean Cryosph a Chang Clim. 2019;447-588.

26. IPCC, Portner HO, Roberts DC, Masson-Delmotte V, Zhai P, Tignor M, et al. IPCC the ocean and cryosphere in a changing climate summary for policmakers. IPCC Spec Rep Ocean Cryosph a Chang Clim. 2019; SPM-1-SPM-42.

27 Halpern BS, Walbridge S, Selkoe KA, Kappel CV, Micheli F, D'Agrosa C, et al. A global map of human impact on marine ecosystems. Science. 2008. https://doi.org/10.1126/science.1149345.

28 Halpern BS, et al. Spatial and temporal changes in cumulative human impacts on the world's ocean. Nat Commun. 2015. https://doi.org/10. 1038/ncomms8615.

29 Selim SA, Blanchard JL, Bedford J, Webb TJ. Direct and indirect effects of climate change and fishing on changes in coastal ecosystem services: a historical perspective from the North Sea. Reg Environ Chang. 2016. https://doi.org/10.1007/s10113-014-0635-7.

30. Butchart SHM, Miloslavich P, Reyers B, Adams C, Bennett E, Czúcz B, et al. Chapter 3 assessing progress towards meeting major international objectives related to nature and nature's contributions to people. Brondízio ES, Settele J, Díaz S, Ngo H, editors. Glob Assess Rep Intergov Sci Platf Biodivers Ecosyst Serv Bonn, Ger. IPBES. 2019. https://doi.org/10.5281/zenodo. 3832053.

31. Schultz L, Folke C, Osterblom H, Olsson P. Adaptive governance, ecosystem management, and natural capital. Proc Natl Acad Sci USA. 2015;112:7369-74.

32. Townsend M, Davies K, Hanley N, Hewitt JE, Lundquist CJ, Lohrer AM. The challenge of implementing the marine ecosystem service concept. Front Mar Sci. 2018;5:1-13. https://doi.org/10.3389/fmars.2018.00359.

33. Collaboration for Environmental Evidence. Guidelines and standards for evidence synthesis in environmental management. Version 5.0. 2018.

34. Haddaway NR, Macura B, Whaley P, Pullin AS. ROSES for systematic map protocols. Version 1.0. 2017. https://doi.org/10.6084/m9.figshare.5897284. Accessed 20 Sept 2021.

35. Harzing A. Publish or perish 2007. https://harzing.com/resources/publi sh-or-perish. Accessed 22 July 2021.

36. Haddaway NR, Collins AM, Coughlin D, Kirk S. The role of google scholar in evidence reviews and its applicability to grey literature searching. PLoS ONE. 2015;10:1-17. https://doi.org/10.1371/journal.pone.0138237.

37 Roessig JM, Woodley CM, Cech JJ Jr, Hansen $\sqcup$. Effects of global climate change on marine and estuarine fishes and fisheries. Rev Fish Biol Fish. 2004. https://doi.org/10.1007/s11160-004-6749-0.

38. Cohen J. Weighted kappa: nominal scale agreement provision for scaled disagreement or partial credit. Psychol Bull. 1968;70:213-20.

39. Landis JR, Koch GG. The measurement of observer agreement for categorical data. Biometrics. 1977;33:159. https://doi.org/10.2307/2529310.

40. Lausch A, Bannehr L, Beckmann M, Boehm C, Feilhauer H, Hacker JM, et al. Linking earth observation and taxonomic, structural and functional biodiversity: local to ecosystem perspectives. Ecol Indic. 2016;70:317-39. https://doi.org/10.1016/j.ecolind.2016.06.022.

41 Bruford MW, Brummitt N, Butchart SHM, Cardoso AC, Coops NC, Dulloo E. Essential biodiversity variables. Science. 2013;339:277-8.
42. Langridge J, Sordello R, Reyjol Y. Outcomes of wildlife translocations in protected areas: what is the type and extent of existing evidence? A systematic map protocol. Environ Evid. 2020;9:1-11. https://doi.org/10. 1186/s13750-020-00199-4.

43. IPBES. Global assessment report of the intergovernmental science-policy platform on biodiversity and ecosystem services. IPBES secretariat, Bonn, Germany. 2019.

44. Pereira HM, Ferrier S, Walters M, Geller GN, Jongman RHG, Scholes RJ, et al. Essential biodiversity variables. Science. 2013;339:277-8. https://doi. org/10.1126/science.1229931.

45. Millenium Ecosystem Service Assessment. Ecosystem services and human well-being. 2005;1-6.

\section{Publisher's Note}

Springer Nature remains neutral with regard to jurisdictional claims in published maps and institutional affiliations.
Ready to submit your research? Choose BMC and benefit from:

- fast, convenient online submission

- thorough peer review by experienced researchers in your field

- rapid publication on acceptance

- support for research data, including large and complex data types

- gold Open Access which fosters wider collaboration and increased citations

- maximum visibility for your research: over $100 \mathrm{M}$ website views per year

At BMC, research is always in progress.

Learn more biomedcentral.com/submissions 